\title{
Nonlinear impact of traction rod on the dynamics of a high- speed rail vehicle carbody
}

\author{
Vahid Bokaeian ${ }^{1,2}$, Mohammad Ali Rezvani ${ }^{1}$ and Robert Arcos $^{3}$ \\ ${ }^{1}$ Center of Excellence in Railway Transportation, School of Railway Engineering, Iran University of Science and Technology, Tehran, Islamic Republic of Iran, \\ ${ }^{2}$ Acoustical and Mechanical Engineering Laboratory, Universitat Politècnica de Catalunya, Spain, \\ ${ }^{3}$ Serra Húnter fellow, Acoustical and Mechanical Engineering Laboratory, Universitat Politècnica de Catalunya, Spain.
}

Keywords: Bounce vibration; Elastic vibrations of carbody; Nonlinear vibrations; Railway vehicle dynamics; Ride quality index.

Correspondence to: Mohammad Ali Rezvani / rezvani_ma@iust.ac.ir

\begin{abstract}
This research is concerned with bogie-carbody nonlinear dynamic interaction of a Shinkansen high-speed rail vehicle. The EulerBernoulli beam model is used to simulate vertical elastic vibrations of carbody. As a novelty, the traction rod that connects the bogie frame and the carbody is considered a nonlinear element. The equivalent linearization method is used to analyze the nonlinear vehicle system in the frequency domain. The analytical spectrum solution compared with the measured data from the running test and the numerical solution in the time domain. When the dynamic interaction due to the carbody's flexibility is considered as nonlinear rather than linear, the maximum amplitude of the bounce acceleration relevant to the first bending mode increases by 38.2 percent at the travel speed of $300 \mathrm{~km} / \mathrm{h}$. With the inclusion of the nonlinear interaction, ride comfort improvement is achievable. It is also feasible to manipulate the vehicle's ride comfort by altering its bogiebase.
\end{abstract}

\section{Introduction}

Amongst many duties, the manufacturers of railway passenger vehicles are also focused on reducing the vehicle's axle loads. This arises from people needing to travel faster, causing the tendency of operating companies to increase travel speed. One option to reduce axle loads is the reduction of the carbody's weight. However, reducing the carbody's weight increases the carbody's flexural vibrations [1-7]. Tomioka and Takigami [1] demonstrated the existence of the bogie-carbody dynamic interaction, which comes from the carbody's bending deformation. They assumed the traction rod to be a linear element [1]. Several studies provided new insights into the ride comfort in high-speed rail vehicles. Graa et al. (2016) [8] developed a reduced dynamic model to assess the ride comfort of railway vehicles. Their research determined that the ride comfort is influenced significantly by the position of the seats and the vehicle's speed. Mizrak and Esen (2017) [9] improved the passenger rail vehicle's comfort with the fuzzy logic method. Antunes et al. (2018) [10] coupled a rigid multi-body model of the railway vehicle and a finite element model of the flexible track to consider the interaction between track and rolling stock.

Pradhan and Samantaray (2018) [11] proposed an integrated multi-body dynamic model of human and railway vehicle to investigate the ride comfort of the passengers, while the carbody considered as a flexible body. Sharma and Kumar (2018) [12] proposed to use semi-active magnetorheological fluid dampers in secondary suspension to enhance the level of travel comfort for a railway vehicle. Ling et al. (2018) [13] reviewed the impact of flexural vibrations of the carbody on the ride comfort and running safety of a high-speed rail vehicle. Dumitriu and Stanica (2019) [14] studied the bounce vibration of a railway vehicle with an elastic carbody. Their research indicated that the most crucial factors in the bending elastic vibrations of the carbody are the carbody's structural features, the damping coefficient of the secondary suspension, also the vehicle running speed. Xu et al. (2019) [15] developed an elastic carbody and human body model to analyze the impressions of the wheel-rail wear and also rail grinding on the ride quality of passengers. Guo et al. (2019) [16] studied the carbody's flexible vibration coupled with the suspended equipment under the carbody. Their study demonstrated that placing equipment heavier than two tons near the carbody center can attenuate the carbody's structural vibrations. Also, their research indicated that placing medium-weight equipment close to the ends of the carbody is an excellent solution to reduce the hunting oscillation that arises from bogies. Besides, it is advised to use a rigid connection for light equipment [16]. Zheng et al. (2019) [17] suppressed the carbody's rigid and flexural vibrations of a railway vehicle by combining the structural damping and active suspension control. Bokaeian et al. (2019) [3] considered the simultaneous effects of bending and twisting elastic deformations of the carbody on the bounce and the ride quality of a high-speed vehicle. Their investigation demonstrated that for the frequencies between $4 \mathrm{~Hz}$ to $20 \mathrm{~Hz}$, the carbody's flexible twisting mode affects its vertical acceleration, particularly close to the carbody's wall. Sun et al. (2019) [18] improved the ride quality index of a high-speed train by using a high static and low dynamic stiffness (HSLDS) vibration isolator. Bruni et al. (2020) [19] reviewed the application of the multibody dynamic approaches to investigate the vehicle's dynamic behavior, including railway vehicles, road vehicles, motorcycles, and bicycles. Magalhães et al. (2020) [20] proposed a new non-Hertzian contact approach to apply in railway vehicle simulations. Xiao et al. (2020) [21] improved the roll stability of a road vehicle via an active roll control system based on electro-hydraulic suspension.

Since the dynamic interaction between the carbody's bending vi- 
bration and longitudinal vibration of the bogies arises from the presence of the traction rod, modeling the traction rod as a nonlinear element instead of a linear one may influence the simulated dynamic response of the rail vehicle. Contrary to the previous research by Tomioka and Takigami [1], in which the traction rod was assumed as a linear element, the principal goal of this research is to analyze the influence of the traction rod's nonlinearity on the vibrational behavior of the Shinkansen railway vehicle. Therefore, this study aimed to answer the following questions: Is it reasonable to consider the traction rod as a nonlinear element? What would be the impact of a nonlinear traction rod on the dynamic behavior of the vehicle? Given the complexity of solving nonlinear systems numerically, is this assumption justifiable?

In the present study, a particular traction rod system is experimentally characterized, demonstrating a stable nonlinear behavior. Also, due to the following advantages, the spectrum analysis is preferred over the time-domain analysis. As the model is randomly excited, the frequency domain analysis allows a significant reduction in computational costs. It also facilitates considering the impact of the nonlinear model of the traction rod on the spectrum analysis of the vehicle model at the frequency range, which is essential regarding the ride quality. For the evaluation of the ride quality, it is more straightforward to apply the frequency filter to the resultant acceleration. A frequency-domain model can be easily coupled with flexible models of the track, which may lead to more detailed models that can be studied in future works. There are several methods, such as perturbation based methods, linearization methods, equivalent linearization method, etc. to solve a nonlinear set of motion equations in the frequency domain. This research uses the equivalent linearization method for frequency analyzes of a nonlinear system. The frequency response is achieved by the equivalent linearization method. The results are compared with some reported experimental tests and the outcome from solving the system in the time domain. The equivalent linearization method is found to be reasonably accurate for this problem. The effects of the inclusions of the linear and nonlinear traction rod ele- ments are investigated.

\section{Modeling}

Figure 1 presents a dynamic idealization of the Shinkansen highspeed railway vehicle (series 100) that is studied in this research. The equations of rigid and flexible motions for the vehicle are extracted according to the following presumptions.

1. The rigid multi-body system of the vehicle includes a carbody and two bogie frames with two wheelsets. The carbody is considered as a rigid-flexible body while the bogie frames and the wheelsets are modeled as rigid bodies. Table 1 lists the allocated rigid degrees of freedom (DOF) for the railway vehicle.

Table 1. Degrees of freedom for the railway vehicle.

\begin{tabular}{llll}
\hline & \multicolumn{3}{c}{ Type of motion } \\
\cline { 2 - 4 } Body & Bounce & Surge & Pitch \\
\hline Carbody & $z_{c}$ & $x_{c}$ & $\theta_{c}$ \\
Bogie frames & $z_{b i}$ & $x_{b i}$ & $\theta_{b i}$ \\
Wheelsets & $z_{w i j}$ & - & - \\
\hline
\end{tabular}

2. The normal contact force between the wheel and the rail is modeled by using a linearized Hertzian spring.

3. It is assumed that the wheelsets cannot vibrate in the longitudinal direction. Therefore, the wheel-rail tangential contact forces are eliminated.

4. In order to model the elastic vibrations of the carbody, the EulerBernoulli beam model under free-free boundary conditions is used. Hence, it is considered that the carbody as a beam is under vertical forces and bending moments, which are applied by the secondary suspensions and the traction rods, respectively. The effect of axial forces that are applied by the traction rods on the carbody flexural motion is not considered.

5. The traction rod that is presented in Fig. 1 is the element that longitudinally connects the bogie frames with the carbody and is considered a nonlinear spring. Figure 2 presents the force-deformation behavior of the traction rod element. The bold curve that is pre-

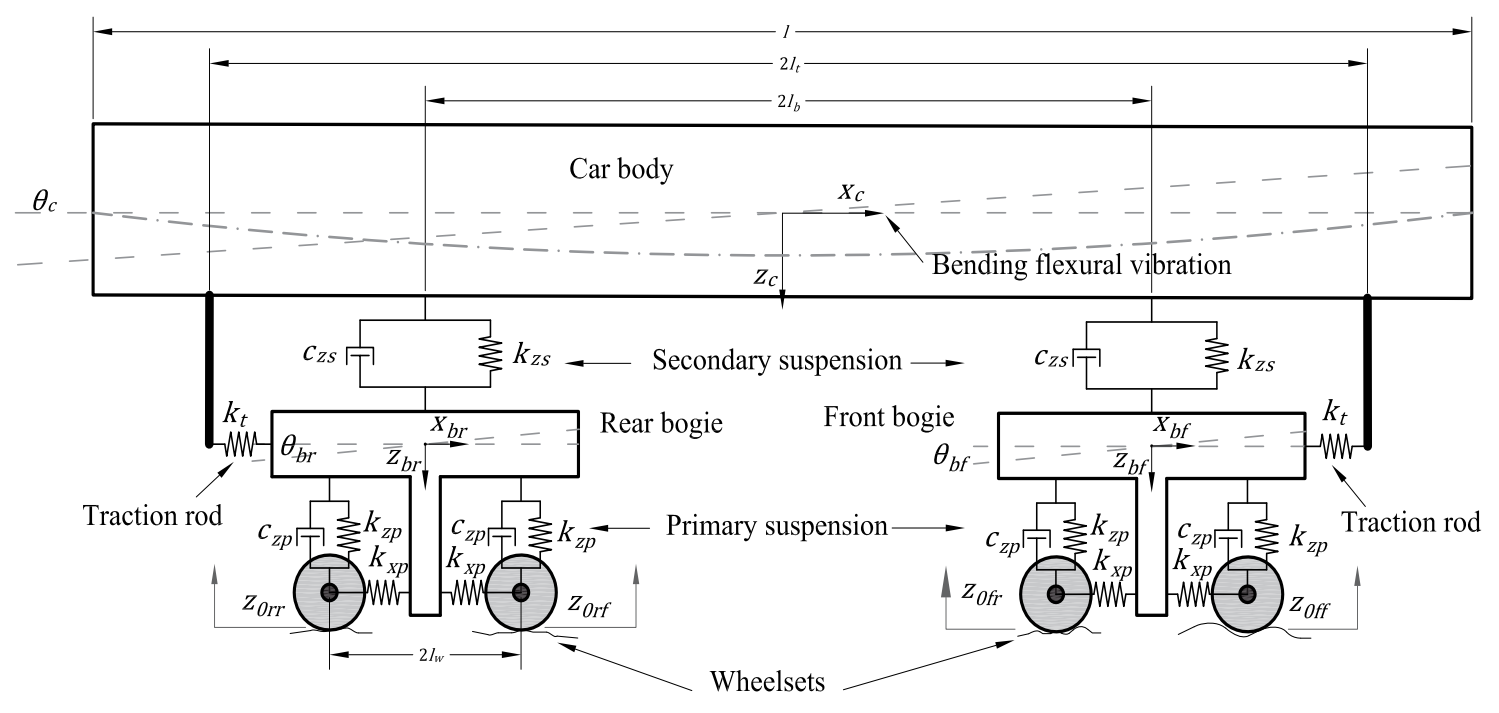

Fig. 1. Dynamic idealization of Shinkansen high-speed rail vehicle (series 100). 

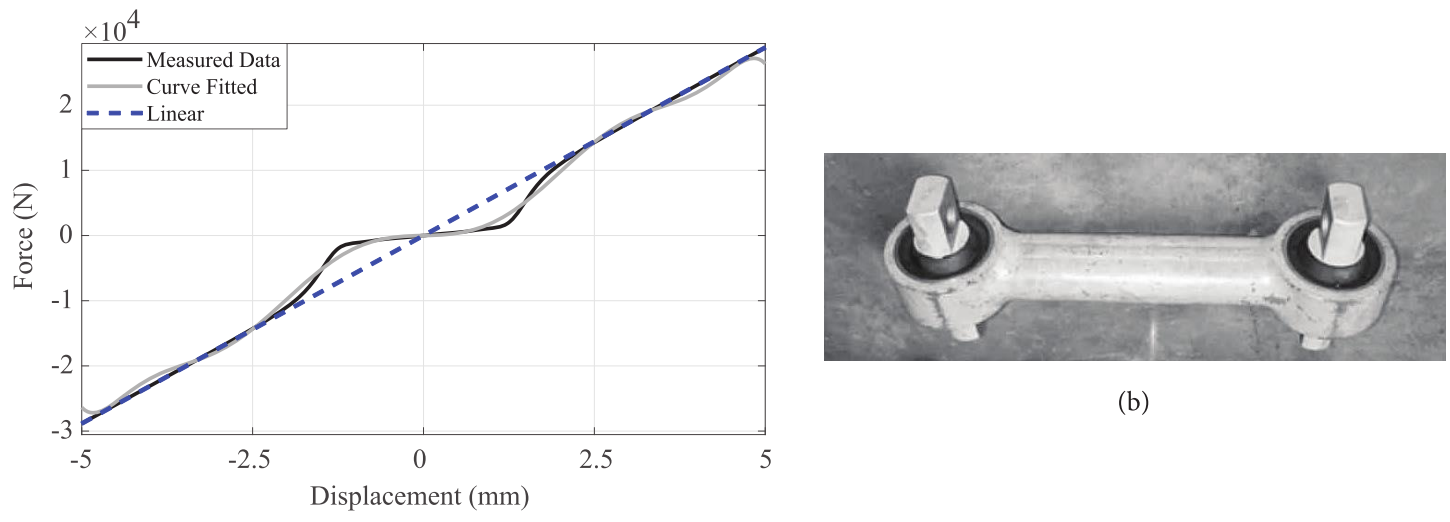

(b)

(a)

Fig. 2. Nonlinear behavior of the traction rod. (a) Nonlinear stiffness of the traction rod and (b) Traction rod[1].

sented in this figure is acquired through an experiment with a dynamometer which was carried out on an elastomer similar to the one that is used in traction rods. The grey line is the fitted curve on the test results. The mathematical approximation of this fitted curve is presented in Eq. (1). The $k_{i}$ coefficients for the stiffness are listed in Table 2. The positioning of the traction rod within the vehicle structure is presented in Fig. 1.

$$
\begin{aligned}
k_{t N L}(\delta)=k_{9} \delta^{8} & +k_{8} \delta^{6}|\delta|+k_{7} \delta^{6}+k_{6} \delta^{4}|\delta| \\
& +k_{5} \delta^{4}+k_{4} \delta^{2}|\delta|+k_{3} \delta^{2}+k_{1}
\end{aligned}
$$

According to Tomioka and Takigami, a dynamic interaction between flexible bending vibrations of the carbody and longitudinal vibrations of the bogie frames exists [1]. Figure 3 simply presents such a phenomenon. As demonstrated, the deformation of the carbody associated with the first bending mode induces a longitudinal motion on points $A$ and $B$. If $z_{c}^{f}(x, t)=\sum_{1}^{N} X_{n}(x) q_{n}(t)$ is the flexible bending deflection of the carbody due to the vertical forces and bending moments that are applied to the carbody in position $x$ at time $t$, then the longitudinal motions that correspond to points $A$ and $B$ are $z_{c}^{f^{\prime}}\left(l_{t f}, t\right) h_{c}$ and $z_{c}^{f^{\prime}}\left(l_{t r}, t\right) h_{c}$, respectively[1]. The prime notation $(')$ denotes the first derivative along the $x$ coordinate. These longitudinal motions cause longitudinal forces between the carbody and the bogie frames due to the presence of the traction rods. As a result, these longitudinal forces induce longitudinal vibrations on the front and rear bogies. It is reminded that the bounces of the points $A$ and $B$ are not considered since these are tiny compared with the corresponding longitudinal motions. This motion makes a dynamic interaction between the flexible bending deformation of the carbody and pitch motions of the bogie frames. The parameters and variables associated with the model presented in Fig. 1 are defined in the section for nomenclature.

Based on the assumptions above, the carbody's equations of motions are the ones that are presented partly in Eqns. (2) to (4) and partly in Eq. (12), which account for its rigid motions (including bounce, surge, and pitch) and flexible vertical deflections, respectively.

$$
\begin{aligned}
& m_{c} \ddot{x}_{c}=-f_{t f}-f_{t r}-f_{y f}-f_{y r} \\
& m_{c} \ddot{z}_{c}^{r}=-f_{z s f}-f_{z s r} \\
& I_{c y} \ddot{\theta}_{c}=l_{b} f_{z s f}-l_{b} f_{z s r}-h_{c} f_{t f}-h_{c} f_{t r}-h_{y} f_{y f}-h_{y} f_{y r}
\end{aligned}
$$

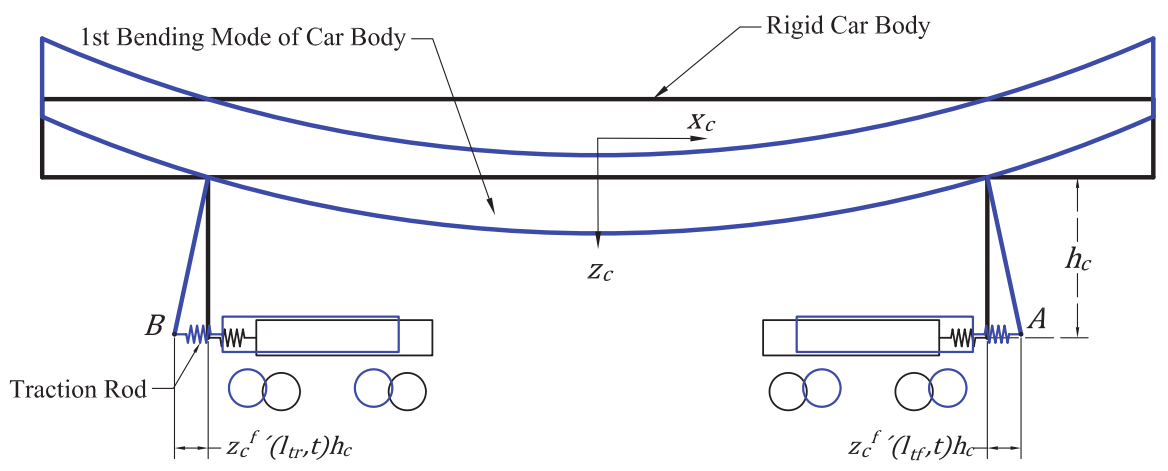

Fig. 3. Schematic of the bogie-carbody dynamic interaction. 
Table 2. Coefficients of the fitted curve to the experimental diagram.

\begin{tabular}{ccc}
\hline Coefficient & Value & Unit \\
\hline$k_{1}$ & $2.774 \times 10^{4}$ & $\mathrm{~N} \cdot \mathrm{m}^{-1}$ \\
$k_{3}$ & $1.856 \times 10^{12}$ & $\mathrm{~N} \cdot \mathrm{m}^{-3}$ \\
$k_{4}$ & 13.56 & $\mathrm{~N} \cdot \mathrm{m}^{-4}$ \\
$k_{5}$ & $-2.128 \times 10^{17}$ & $\mathrm{~N} \cdot \mathrm{m}^{-5}$ \\
$k_{6}$ & $-9.858 \times 10^{5}$ & $\mathrm{~N} \cdot \mathrm{m}^{-6}$ \\
$k_{7}$ & $9.917 \times 10^{21}$ & $\mathrm{~N} \cdot \mathrm{m}^{-7}$ \\
$k_{8}$ & $2.194 \times 10^{10}$ & $\mathrm{~N} \cdot \mathrm{m}^{-8}$ \\
$k_{9}$ & $-1.622 \times 10^{26}$ & $\mathrm{~N} \cdot \mathrm{m}^{-9}$ \\
\hline
\end{tabular}

In Eq. (2), $f_{t f}$ and $f_{t r}$ are the longitudinal forces between the carbody and the front and the rear bogie frames due to the traction rod, respectively. Similarly, $f_{y f}$ and $f_{y r}$ are the longitudinal forces between the carbody and the front and the rear bogies due to the yaw damper, respectively. These interaction forces are defined in Eqns. (5) and (6).

$$
\begin{gathered}
f_{t i}=k_{t} \delta_{t i} \\
\delta_{t i}=x_{c}+h_{c} \sum_{n=3}^{N} X_{n}^{\prime}\left(l_{t i}\right) q_{n}-x_{b i} \\
f_{y i}=k_{y} \delta_{y i}+c_{y} \dot{\delta}_{y i} \\
\delta_{y i}=x_{c}+h_{y} \sum_{n=3}^{N} X_{n}^{\prime}\left(l_{y i}\right) q_{n}-x_{b i}
\end{gathered}
$$

where $\delta_{t i}$ and $\delta_{y i}$ are the longitudinal displacement between the carbody in $i$ th bogie frame at the position of the traction rod and yaw damper connections, respectively. The longitudinal movements of the carbody and the bogie frames due to their pitch motions neglected, as they are minor compared to the other terms that appear in Eqns. (5) and (6). Also, in Eqns. (3) and (4), $f_{z s i}$ represents the vertical forces between the $i$ th bogie frame and the carbody due to the secondary suspension system, and defined by Eq. (7).

$f_{z s f}=k_{z s}\left[z_{c}\left(l_{f}, t\right)-z_{b f}\right]+c_{z s}\left[\dot{z}_{c}\left(l_{f}, t\right)-\dot{z}_{b f}\right]$

$f_{z s r}=k_{z s}\left[z_{c}\left(l_{r}, t\right)-z_{b r}\right]+c_{z s}\left[\dot{z}_{c}\left(l_{r}, t\right)-\dot{z}_{b r}\right]$

where $z_{c}(x, t)$ is the global bounce motion of the carbody, including the rigid and flexible motions at the longitudinal position $\mathrm{x}$ and time $t$, which is defined by Eq. (8).

$$
z_{c}(x, t)=z_{c}^{r}(t)+\left(l_{c}-x\right) \theta_{c}(t)+z_{c}^{f}(x, t)
$$

The carbody is modeled as a beam with free-ends boundary condition subjected to vertical forces that arise from the secondary suspension $\left(f_{z s i}\right)$ and bending moments due to the longitudinal forces of the traction $\operatorname{rod}\left(M_{t}=f_{t i} h_{c}\right)$ and yaw damper $\left(M_{y}=f_{y i} h_{y}\right)$. Thus, the partial differential equation (PDE) for carbody's bending deformation, based on the Euler-Bernoulli beam considering flexural rigidity $E I$, internal damping coefficient $\mu$, density $\rho$, and cross-sectional area $A$ is written as [22]

$$
\begin{array}{r}
E I \frac{\partial^{4} z_{c}(x, t)}{\partial x^{4}}+\mu I \frac{\partial^{5} z_{c}(x, t)}{\partial t \partial x^{4}}+\rho A \frac{\partial^{2} z_{c}(x, t)}{\partial t^{2}}= \\
-f_{z s f} \delta\left(x-l_{f}\right)-f_{z s r} \delta\left(x-l_{r}\right) \\
-\frac{f_{t f} h_{c}}{\Delta}\left[\delta\left(x-l_{t f}\right)-\delta\left(x-\left(l_{t f}+\Delta\right)\right)\right] \\
+\frac{f_{t r} h_{c}}{\Delta}\left[\delta\left(x-l_{t r}\right)-\delta\left(x-\left(l_{t r}+\Delta\right)\right)\right] \\
-\frac{f_{y f} h_{y}}{\Delta}\left[\delta\left(x-l_{y f}\right)-\delta\left(x-\left(l_{y f}+\Delta\right)\right)\right] \\
+\frac{f_{y r} h_{y}}{\Delta}\left[\delta\left(x-l_{y r}\right)-\delta\left(x-\left(l_{y r}+\Delta\right)\right)\right]
\end{array}
$$

where $\Delta$ is the longitudinal distance between the equivalent coupled forces and the acting point of the moment. $\Delta$ is used to convert the applied bending moment to applied forces. $\delta\left(x-l_{i j}\right)$ is the Dirac delta function. Solving the PD Eq. (9) by mode decomposition, the flexible bounce motion of the carbody is, $z_{c}^{f}(x, t)=\sum_{n=1}^{N} X_{n}(x) q_{n}(t)$, where the $X_{n}(x)$ and $q_{n}(t)$ are the mode shape function and the modal coordinate of the nth mode, respectively. The first two terms on the right side of the Eq. (8) already represent the rigid body modes of the carbody, which are not taken into account in the mode summation for obtaining $z_{c}^{f}$. For $\mathrm{n} \geq 3$, the corresponding flexural mode shape functions for a free-free beam are

$$
\begin{aligned}
& X_{n}(x)=\cosh \beta_{i} x+\cos \beta_{i} x- \\
& \frac{\cos \beta_{i} l-\cos \beta_{i} l}{\sinh \beta_{i} l-\sin \beta_{i} l} \times\left(\sinh \beta_{i} x+\sin \beta_{i} x\right)
\end{aligned}
$$

where $\beta_{i}$ can be obtained by solving

$$
1-\cosh \beta_{i} l \cos \beta_{i} l=0
$$

Substituting $Z_{c}^{f}(x, t)=\sum_{n=1}^{N} X_{n}(x) q_{n}(t)$ into the Eq. (9), integrating along 1 and bearing in mind the orthogonality of the shape functions, the equation for the flexible motion of the carbody is as follow;

$$
\begin{gathered}
\ddot{q}_{n}+2 \xi_{n} \omega_{n} \dot{q}_{n}+\omega_{n}^{2} q_{n}=\frac{1}{\rho A l}\left[-f_{z s f} X_{n}\left(l_{f}\right)\right. \\
-f_{z s r} X_{n}\left(l_{r}\right)+f_{t f} h_{c} X_{n}^{\prime}\left(l_{t f}\right)-f_{t r} h_{c} X_{n}^{\prime}\left(l_{t r}\right) \\
\left.+f_{y f} h_{y} X_{n}^{\prime}\left(l_{y f}\right)-f_{y r} h_{y} X_{n}^{\prime}\left(l_{y r}\right)\right] \\
\omega_{n}^{2}=\beta_{n}^{4} \frac{E I}{\rho A}, \quad 2 \zeta_{n} \omega_{n}=\beta_{n}^{4} \frac{\mu I}{\rho A}
\end{gathered}
$$

where $\omega_{n}$ and $\xi_{n}$ are the natural frequency and structural damping coefficient for the nth bending mode of the carbody, respectively. Takigami and Tomioka [23] identified the flexural mode shapes of the Shinkansen high-speed railway vehicle with aluminum alloy carbody in stationary and running tests. They demonstrated that the carbody's shape modes at around the frequencies of $9.84 \mathrm{~Hz}$ and $15.12 \mathrm{~Hz}$ are similar to the two first bending modes of a beam with 
free-ends boundary conditions, respectively. Hence, for the sake of the present work, these are considered as the frequencies of the first and the second flexural bending modes of the carbody.

Regarding the bogie frame, the equations of motion are

$$
\begin{aligned}
& m_{b} \ddot{x}_{b i}=k_{t} \delta_{t i}+k_{y} \delta_{y i}+c_{y} \dot{\delta}_{y i}-2 k_{x p} x_{b i} \\
& m_{b} \ddot{z}_{b i}=k_{z s}\left[z\left(l_{i}, t\right)-z_{b i}\right]+c_{z s}\left[\dot{z}\left(l_{i}, t\right)-\dot{z}_{b i}\right] \\
& -k_{z p}\left[\left(z_{b i}-l_{w} \theta_{b i}\right)-z_{w i f}\right]-c_{z p}\left[\left(\dot{z}_{b i}-l_{w} \dot{\theta}_{b i}\right)-\dot{z}_{w i f}\right] \\
& -k_{z p}\left[\left(z_{b i}+l_{w} \theta_{b i}\right)-z_{w i r}\right]-c_{z p}\left[\left(\dot{z}_{b i}+l_{w} \dot{\theta}_{b i}\right)-\dot{z}_{w i r}\right] \\
& I_{b y} \ddot{\theta}_{b i}=l_{w} k_{z p}\left[\left(z_{b i}-l_{w} \theta_{b i}\right)-z_{w i f}\right] \\
& +l_{w} c_{z p}\left[\left(\dot{z}_{b i}-l_{w} \dot{\theta}_{b i}\right)-\dot{z}_{w i f}\right] \\
& -l_{w} k_{z p}\left[\left(z_{b i}+l_{w} \theta_{b i}\right)-z_{w i r}\right] \\
& -l_{w} c_{z p}\left[\left(\dot{z}_{b i}+l_{w} \dot{\theta}_{b i}\right)-\dot{z}_{w i r}\right]-2 h_{b} k_{x p} x_{b i}
\end{aligned}
$$

where sub-index $i$ must be swapped by $f$ or $r$ to achieve the equations of motions for the front or the rear bogie frames, correspondingly.

The equations of motions for the wheelsets of the $i$ th bogie frame are

$$
\begin{gathered}
m_{w} \ddot{z}_{w i f}=k_{z p}\left[\left(z_{b i}-l_{w} \theta_{b i}\right)-z_{w i f}\right] \\
+c_{z p}\left[\left(\dot{z}_{b i}-l_{w} \dot{\theta}_{b i}\right)-\dot{z}_{w i f}\right]-N_{w i f} \\
m_{w} \ddot{z}_{w i r}=k_{z p}\left[\left(z_{b i}+l_{w} \theta_{b i}\right)-z_{w i r}\right] \\
+c_{z p}\left[\left(\dot{z}_{b i}+l_{w} \dot{\theta}_{b i}\right)-\dot{z}_{w i r}\right]-N_{w i r}
\end{gathered}
$$

where sub-index $i$ must be swapped by $f$ or $r$ to acquire the equations of motions of the wheelsets of the front or the rear bogie frame, respectively. Moreover, $N_{w i j}$ is the wheel-rail normal contact force for the $j$ th wheelset of the $i$ th bogie frame that is defined by

$$
N_{w i j}=k_{h z} \delta_{w i j}, \quad \delta_{w i j}=z_{w i j}-z_{0 i j}
$$

\section{Frequency domain analysis of the nonlinear system}

\subsection{Equivalent linearization method}

In this section, the multi-degrees of freedom nonlinear system previously defined is transformed into the frequency domain by using the equivalent linearization method [24]. Consider a nonlinear model with $N$ degrees of freedom as

$$
\mathbf{M} \ddot{\mathbf{x}}(t)+\mathbf{C} \dot{\mathbf{x}}(t)+\mathbf{K x}(t)+\mathbf{\Phi}(\mathbf{x}(t), \dot{\mathbf{x}}(t), \ddot{\mathbf{x}}(t))=\mathbf{q}(t)
$$

where $\mathbf{M}, \mathbf{C}$, and $\mathbf{K}$ are the mass, damping, and stiffness matrices of the system, respectively. Also, $\boldsymbol{\Phi}$ is the nonlinear force vector, and $\mathbf{q}(t)$ is the exciting random vector. An equivalent linear system of equations to the nonlinear system presented in Eq. (20) is written as

$$
\left(\mathbf{M}+\mathbf{M}_{e}\right) \ddot{\mathbf{x}}(t)+\left(\mathbf{C}+\mathbf{C}_{e}\right) \dot{\mathbf{x}}(t)+\left(\mathbf{K}+\mathbf{K}_{e}\right) \mathbf{x}=\mathbf{q}(t)
$$

where $\mathbf{M}_{e}, \mathbf{C}_{e}$, and $\mathbf{K}_{e}$ are the mass, damping, and stiffness matrices due to the system's nonlinearity that needs to be added to the corresponding linear system components to acquire the equivalent linear system. Such matrices need to be calculated in an approach that minimizes the error vector $\mathbf{e}$ in Eq. (22). The error vector is then equal to the difference between the nonlinear and the equivalent linear system responses. Thus,

$$
\begin{aligned}
& \mathbf{e}=\mathbf{M} \ddot{\mathbf{x}}+\mathbf{C} \dot{\mathbf{x}}+\mathbf{K x}+\boldsymbol{\Phi}(\mathbf{x}, \dot{\mathbf{x}}, \ddot{\mathbf{x}})- \\
& {\left[\left(\mathbf{M}+\mathbf{M}_{e}\right) \ddot{\mathbf{x}}+\left(\mathbf{C}+\mathbf{C}_{e}\right) \dot{\mathbf{x}}+\left(\mathbf{K}+\mathbf{K}_{e}\right) \mathbf{x}\right]} \\
& =\boldsymbol{\Phi}(\mathbf{x}, \dot{\mathbf{x}}, \ddot{\mathbf{x}})-\left[\mathbf{M}_{e} \ddot{\mathbf{x}}+\mathbf{C}_{e} \dot{\mathbf{x}}+\mathbf{K}_{e} \mathbf{x}\right]
\end{aligned}
$$

In Eqns. (21) and (22), the matrices $\mathbf{M}_{\boldsymbol{e}}, \mathbf{C}_{\boldsymbol{e}}$, and $\mathbf{K}_{\boldsymbol{e}}$ depend on $\mathbf{x}(t)$, and $\mathbf{x}(t)$ depends on $\mathbf{M}_{\boldsymbol{e}}, \mathbf{C}_{\boldsymbol{e}}$, and $\mathbf{K}_{\boldsymbol{e}}$. Therefore, there is a cyclic relation between $\mathbf{M}_{\boldsymbol{e}}, \mathbf{C}_{\boldsymbol{e}}$, and $\mathbf{K}_{\boldsymbol{e}}$ matrices and $\mathbf{x}(t)$. To obtain $\mathbf{M}_{e}, \mathbf{C}_{e}$, and $\mathbf{K}_{e}$ matrices, it is necessary to define a criterion to minimize the error vector $\mathbf{e}$. Therefore, in the following, the $\mathrm{Eu}-$ clidean norm of the error vector $\|\mathbf{e}\|^{2}=\mathbf{e}^{\mathrm{T}} \mathbf{e}$ will be used as the objective function to be minimized. It can be proven that to minimize this objective function, the $\mathbf{M}_{e}, \mathbf{C}_{e}$, and $\mathbf{K}_{e}$ elements should be calculated according to Eq. (23). The corresponding procedure can be followed in Robert and Spanos [24].

$$
\begin{gathered}
m_{i j}^{e}=E\left[\frac{\partial \Phi_{i}}{\partial \ddot{\mathbf{x}}_{j}}\right] \\
c_{i j}^{e}=E\left[\frac{\partial \Phi_{i}}{\partial \dot{\mathbf{x}}_{j}}\right] \\
k_{i j}^{e}=E\left[\frac{\partial \Phi_{i}}{\partial \mathbf{x}_{j}}\right]
\end{gathered}
$$

Equation (23) is used to obtain $\mathbf{M}_{\mathrm{e}}, \mathbf{C}_{\mathrm{e}}$, and $\mathbf{K}_{\mathrm{e}}$ matrices of the equivalent linear system. By considering the yaw dampers as linear elements and neglecting the nonlinearity of the air springs, the remaining nonlinearity is only related to the displacement. The equation of the nonlinear system is

$$
\mathbf{M} \ddot{\mathbf{x}}(t)+\mathbf{C} \dot{\mathbf{x}}(t)+\mathbf{K x}(t)+\mathbf{\Phi}(\mathbf{x})=\mathbf{q}(t)
$$

where, in this case, $\boldsymbol{\Phi}$ is the nonlinear vector due to the traction rod stiffness, and $\mathbf{q}(t)$ is the random excitation with zero mean value. The first step to define the equivalent linear system is using Eq. (23). For the vehicle system that is modeled in this study, $m_{i j}^{e}, c_{i j}^{e}$ are zero, and the elements of $k_{i j}^{e}$ should be calculated by using Eq. (25). 


$$
k_{i j}^{e}=E\left[\frac{\partial \Phi_{i}}{\partial \mathbf{x}_{j}}\right]
$$

The nonlinear vector $\boldsymbol{\Phi}$ is defined as;

$$
\boldsymbol{\Phi}(\mathbf{x})=\left\{\begin{array}{c}
f_{t N L} \\
0 \\
h_{c}\left(f_{t f N L}+f_{t r N L}\right) \\
-f_{t f N L} \\
0 \\
-h_{b} f_{t f N L} \\
-f_{t r N L} \\
0 \\
-h_{b} f_{t r N L} \\
{[0]_{4 \times 1}} \\
2 h_{c}\left[f_{t f N L} X_{1}^{\prime}\left(l_{t f}\right)+f_{t r N L} X_{1}^{\prime}\left(l_{t r}\right)\right] / m \\
2 h_{c}\left[f_{t f N L} X_{2}^{\prime}\left(l_{t f}\right)+f_{t r N L} X_{2}^{\prime}\left(l_{t r}\right)\right] / m
\end{array}\right\}
$$

In Eq. (1), the dynamic behavior of the traction rod can be divided into the linear and the nonlinear parts as follow

$$
\begin{aligned}
& f_{t i}=f_{t i L}+f_{t i N L} \\
& f_{t i L}=k_{1} \delta_{t i} \\
& f_{t i N L}=k_{9} \delta_{t i}^{9}+k_{8} \delta_{t i}^{7}\left|\delta_{t i}\right|+k_{7} \delta_{t i}^{7} \\
& +k_{6} \delta_{t i}^{5}\left|\delta_{t i}\right|+k_{5} \delta_{t i}^{5}+k_{4} \delta_{t i}^{3}\left|\delta_{t i}\right|+k_{3} \delta_{t i}^{3}
\end{aligned}
$$

The linear dynamic interaction in Eq. (28), $k_{1}$ needs to be replaced by $k_{t L}$ from Table 3 . Once the elements of the stiffness matrix $\mathbf{K}_{\mathrm{e}}$ are computed by Eq. (25), the second step is to assemble this matrix and solve the resulting equivalent system, which can be written as

$$
\mathbf{M} \ddot{\mathbf{x}}(t)+\mathbf{C} \dot{\mathbf{x}}(t)+\left(\mathbf{K}+\mathbf{K}_{e}\right) \mathbf{x}(t)=\mathbf{q}(t)
$$

The frequency-domain solution of the system of Eq. (30) can be obtained by $\sum_{r=1}^{4} \sum_{s=1}^{4} \mathbf{H}_{d i r}^{*}(\omega) S_{\text {Irs }}(\omega) \mathbf{H}_{\text {dis }}^{T}(\omega)$, where $\mathbf{H}(\omega)$ is the frequency response function (FRF) of the model, and it can be calculated by

$$
\mathbf{H}(\omega)=\left(-\mathbf{M} \omega^{2}+j \omega \mathbf{C}+\mathbf{K}\right)^{-1}
$$

Besides, $S_{o i}(\omega)$ and $S_{I r s}(\omega)$ are the power spectral density (PSD) of the system response and the input excitation matrices, respectively. Therefore, the expected value in Eq. (25) can be calculated by using Eq. (32).

$$
E\left[x_{i}(t) x_{j}(t)\right]=\int_{-\infty}^{\infty} S_{x_{i} x_{j}}(\omega) d \omega
$$

These two steps should be repeated until the outcome of the integral in Eq. (32) becomes constant or smaller than a specific amount. Figure 4 presents the solution algorithm of the equivalent linearization method.

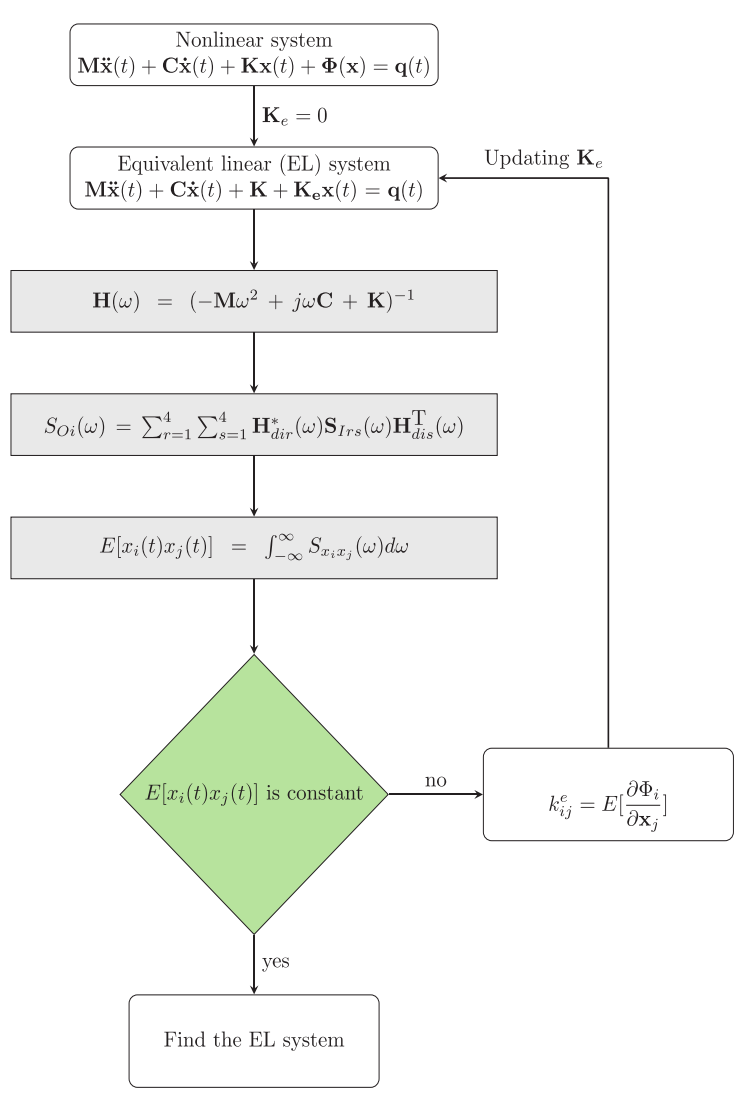

Fig. 4 Solution algorithm in the equivalent linearization method.

\subsection{Model validation}

In this section, the results that are acquired using the equivalent linear system are compared with the numerical solution obtained by using a time-domain solution. The mechanical parameters of the modeled vehicle (Shinkansen series 100) are noted in Table 3. The PSD for the vertical track irregularity is obtained from the FRA standard [25,26], considering a track of class 6 .

Figure 5 illustrates PSD of the carbody's acceleration in the longitudinal direction at the running speed of $300 \mathrm{~km} / \mathrm{h}$ for two cases, including the linear traction rod and the nonlinear traction rod. It is observable that the results obtained from the equivalent linear system have an appropriate agreement with the results achieved through the time domain solution. Figure 5 also presents three important resonances at frequencies $8 \mathrm{~Hz}, 15.12 \mathrm{~Hz}$, and $21 \mathrm{~Hz}$. The resonance at $15.12 \mathrm{~Hz}$ is associated with the second mode of the carbody's flexural bending deformation (see Table 3). The appearance of this mode on the longitudinal acceleration response of the carbody proves the relevancy of the dynamic interaction between the elastic bending defor- 
mation of the carbody and the longitudinal motion of the bogie frames. The other resonance peaks (at $8 \mathrm{~Hz}$ and $21 \mathrm{~Hz}$ ) are related to the natural frequencies due to stiffness of the traction rod and stiffness of the primary suspension system in the longitudinal direction. Besides, it also noticed that these frequencies are different between the two cases of linear and nonlinear interactions. Indeed, the natural frequencies for the nonlinear interaction are smaller; because the corresponding stiffnesses are different.

Table 3. Mechanical characteristics of the Shinkansen vehicle (series 100)[1].

\begin{tabular}{ccccc}
\hline symbol & value & symbol & \multicolumn{2}{c}{ value } \\
\hline$m_{c}$ & $16900 \mathrm{~kg}$ & $m_{b}$ & \multicolumn{2}{c}{$2580 \mathrm{~kg}$} \\
$m_{w}$ & $1510 \mathrm{~kg}$ & $J_{b}$ & \multicolumn{2}{c}{$2340 \mathrm{~kg} \mathrm{~m}^{2}$} \\
$J_{c}$ & $2.1 \times 10^{6}$ & $\mathrm{~kg} \mathrm{~m}^{2}$ & $l$ & \multicolumn{2}{c}{$24.5 \mathrm{~m}$} \\
$l_{w}$ & $1.25 \mathrm{~m}$ & & $l_{b}$ & $8.75 \mathrm{~m}$ \\
$l_{c}$ & $12.25 \mathrm{~m}$ & $l_{f}$ & $21 \mathrm{~m}$ \\
$l_{r}$ & $3.5 \mathrm{~m}$ & $l_{t f}$ & $21.2 \mathrm{~m}$ \\
$l_{t r}$ & $3.3 \mathrm{~m}$ & $l_{y f}$ & $21.66 \mathrm{~m}$ \\
$l_{y r}$ & $2.84 \mathrm{~m}$ & $b$ & $2.2 \mathrm{~m}$ \\
$b_{w}$ & $0.7175 \mathrm{~m}$ & $h_{b}$ & $0.1 \mathrm{~m}$ \\
$h_{c}$ & $0.97 \mathrm{~m}$ & $h_{y}$ & $0.92 \mathrm{~m}$ \\
$k_{z s}$ & $2.65 \times 10^{6} \mathrm{~N} \mathrm{~m}^{-1}$ & $k_{t L}$ & $5.77 \times 10^{6} \mathrm{~N}$ \\
$k_{x p}$ & $8.4 \times 10^{6} \mathrm{~N} \mathrm{~m}^{-1}$ & $k_{h z}$ & $1504 \mathrm{kN} \mathrm{m}^{-1}$ \\
$\xi_{I}$ & $1.2 \%$ & $\xi_{2}$ & $0.3 \%$ \\
$\omega_{l}$ & $9.84 \mathrm{~Hz}^{-1}$ & $\omega_{2}$ & $15.12 \mathrm{~Hz}$ \\
\hline
\end{tabular}
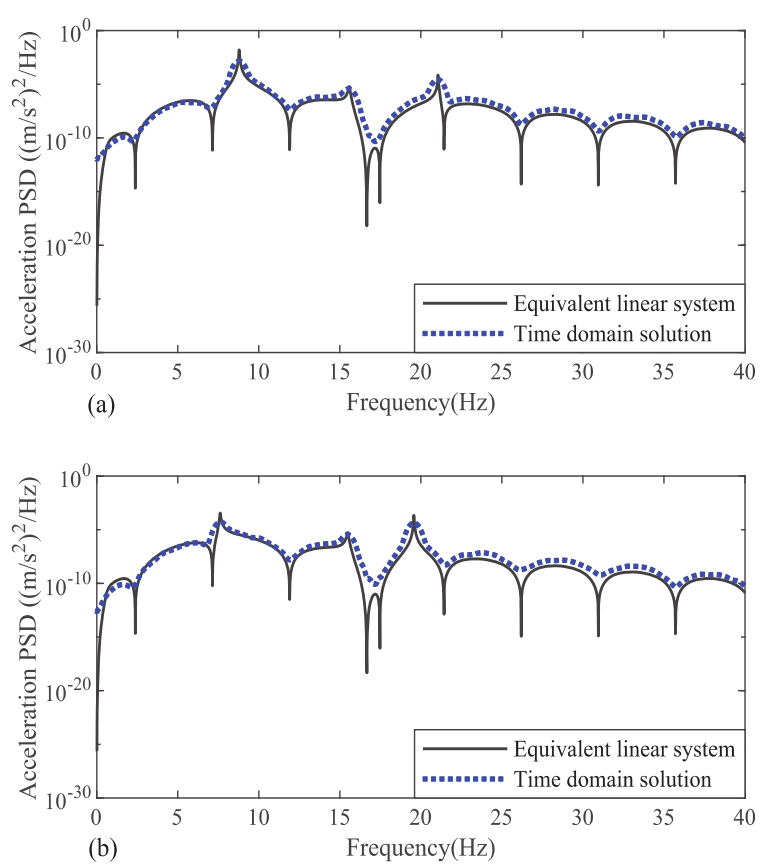

Fig. 5. PSD of the carbody acceleration in the longitudinal $(x)$ direction. (a) Linear interaction and (b) Nonlinear interaction.

Figure 6 compares PSDs of the bounce acceleration, which is measured at the floor of the carbody center through a field test by
Tomioka and Takigami [1], and the simulated bounce acceleration by considering both linear and nonlinear traction rods. Based on this set of data, a good compromise is observed between the measured and simulated results. Besides, there are two resonances in the bounce acceleration response at the floor of the carbody center related to the longitudinal interaction between the carbody and the bogie frames. In Figs. 5 and 6 some anti-resonances appear in the PSD responses of the vehicle. These anti-resonances are related to the filtering effect of the track irregularity. This phenomenon occurs when the summation of the vertical track irregularities of the two bogies of the vehicle or the two wheelsets of a bogie becomes zero. These effects are termed as the bogie-base and the wheel-base averaging effect, respectively. The corresponding frequencies could be obtained via Eq. (33) [1,7].
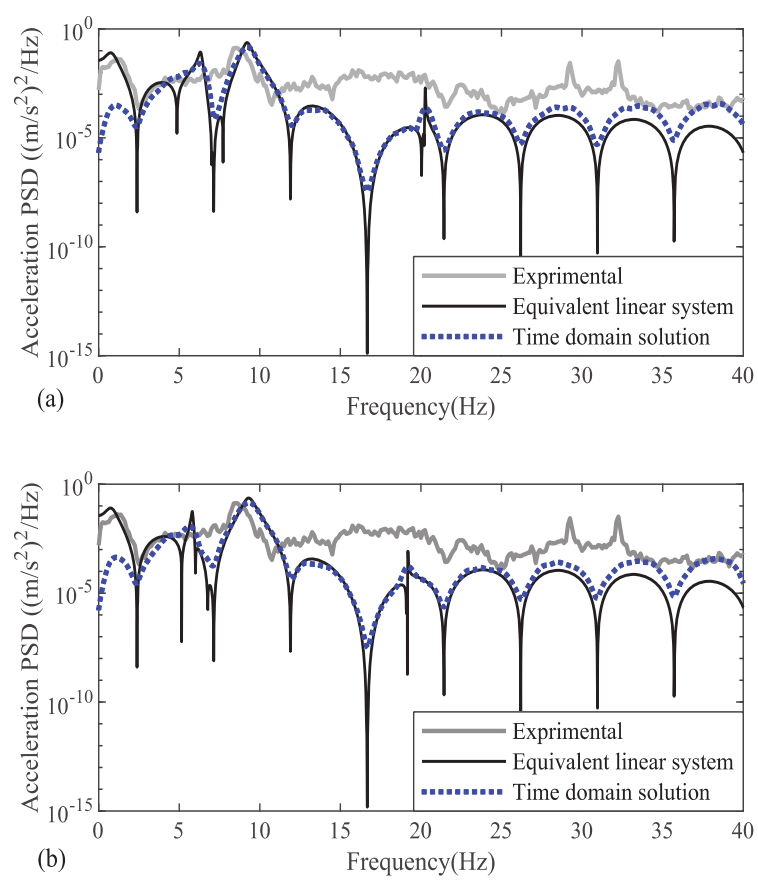

Fig. 6. Running test [1] and analytical results of the bounce acceleration for the center of the carbody floor. (a) Linear interaction and (b) Nonlinear interaction.

$$
\begin{gathered}
f_{b}=\frac{(2 i+1) v}{4 L_{b}}, \quad i=0,1,2, \ldots \\
f_{w}=\frac{(2 j+1) v}{4 L_{w}}, \quad j=0,1,2, \ldots
\end{gathered}
$$

where $f_{b}$ and $f_{w}$ are the frequencies in which the bogie-base and the wheel-base filtering effects occurred, respectively. Based on Eq. (33), the frequencies of the filtering effect depend on the bogie-base or the wheel-base and also on the train velocity.

\section{Results and discussion}

\subsection{Bounce oscillation of the carbody}

Figures 7 and 8 present the spectrum content of the bounce accel- 

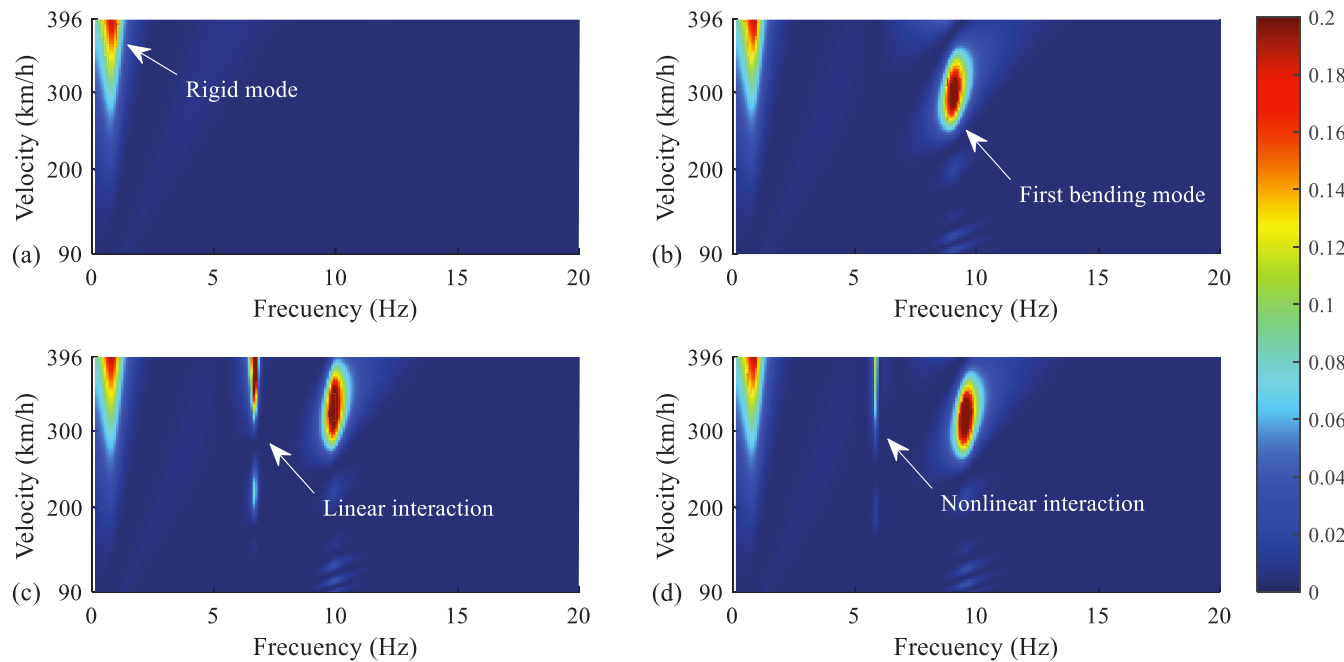

Fig. 7. PSD of bounce acceleration at position C; (a) rigid carbody, (b) flexible carbody without interaction, (c) flexible carbody with linear interaction, and (d) flexible carbody with nonlinear interaction.

eration of the carbody floor at the center and above the front bogie, which is referred to as positions $C$ and $F$, respectively. These figures present four different cases, as follow:

a) Rigid carbody, which represents the case where the carbody assumed rigid. In this case, there is no bogies-carbody interaction. This can be inferred from the carbody's bounce acceleration that is presented in Figs. 7 and 8 (a), since there is only one relevant mode appearing in the spectrum, which is relevant to the secondary suspension system.

b) Flexible carbody without interaction, which represents the case where the carbody is considered as a flexible body, and the effect of the traction rod is not considered. Also, the peaks associated with the flexural bending modes appear in the bounce acceleration of the carbody floor.

c) Flexible carbody with linear interaction, which represents the case where the carbody is supposed to be elastic and the traction rod assumed as a linear element. In this case, besides the rigid and flexural modes, other peaks appear at frequencies of $6.5 \mathrm{~Hz}$ and $20.2 \mathrm{~Hz}$. These peaks are related to the linear interaction in which their amplitude increases by increasing the speed.

d) Flexible carbody with nonlinear interaction, which represents the case where the carbody assumed flexible, and the traction rod assumed with considering the traction rod stiffness as a nonlinear element. A scenario similar to the case (c) also occurs in this case when the frequencies of the peaks relevant to the interaction decreased to $5.5 \mathrm{~Hz}$ and $19.3 \mathrm{~Hz}$, and the amplitudes decreased.

In addition to the above explanations, there are some differences between the bounce acceleration at positions $\mathrm{C}$ and $\mathrm{F}$ as follows.

1. In the frequency response of bounce acceleration at position $\mathrm{C}$, only the first bending mode appears. In contrast, for position $\mathrm{F}$ the first and the second bending modes appear, as expected, taking in-
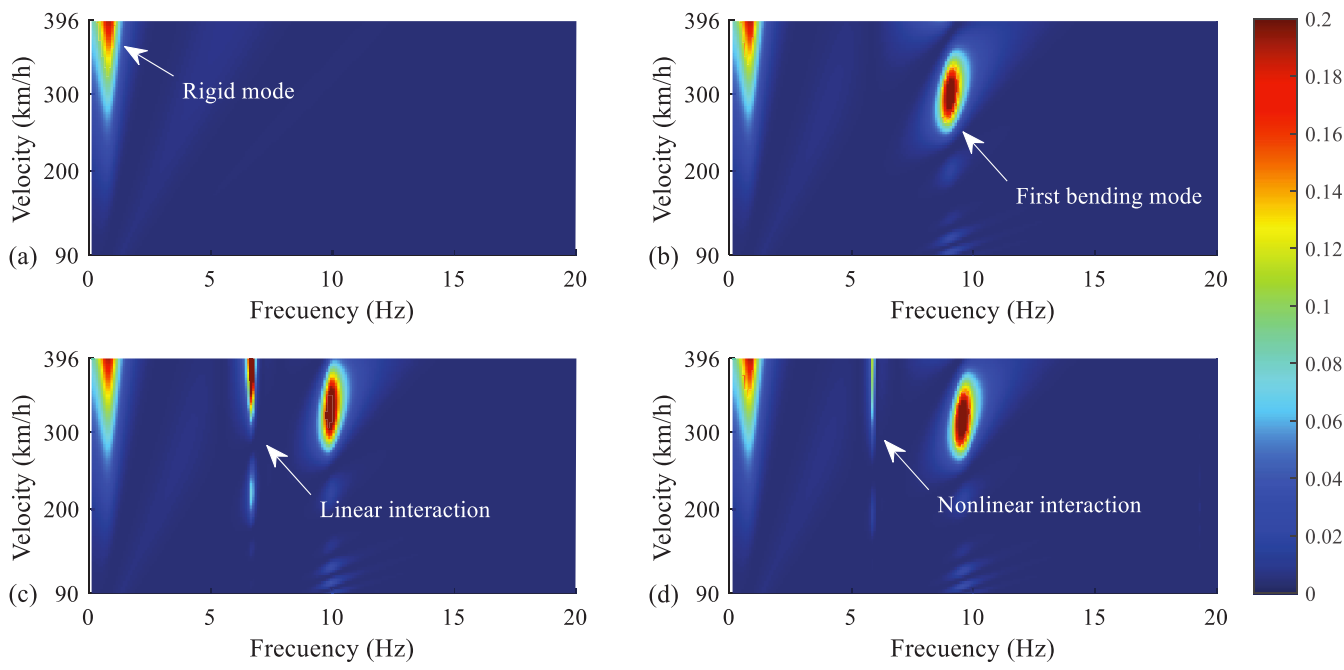

Fig. 8. PSD of bounce acceleration at position F; (a) rigid carbody, (b) flexible carbody without interaction, (c) flexible carbody with linear interaction, and (d) flexible carbody with nonlinear interaction. 
to account the corresponding mode shapes.

2. As the amplitude of the bounce acceleration relevant to the first bending mode at position $\mathrm{C}$ is more prominent than position $\mathrm{F}$; therefore, it anticipated that the ride quality at position $\mathrm{C}$ is worse than position $\mathrm{F}$.

3. The amplitude of the bounce acceleration of the peak related to the interaction at position $\mathrm{F}$ is smaller than position $\mathrm{C}$. As mentioned; the bogie-carbody dynamic interaction arises from the bending flexibility of the carbody. By decreasing the bending deformation of the carbody, the longitudinal forces between the bogies and the carbody decrease. As a result, the amplitude of the bounce acceleration relevant to the interaction will be decreased.

Another point that is deduced from Figs. 7 and 8 is that the carbody behaves like a rigid body under the speed of $200 \mathrm{~km} / \mathrm{h}$. Indeed, the peaks related to the flexural bending modes and, consequently, the peaks associated with dynamic interaction do not appear in the frequency response of the carbody floor's bounce acceleration. This is because of the bogie-base and wheel-base filtering effects, which are explained in detail by Bokaeian et al. [3]. By comparing cases (c) and (d) from both Figs. 7 and 8, it can be observed that when the traction rod stiffness is assumed as a nonlinear element, the amplitude of the bounce acceleration is smaller. This is due to the nonlinear behavior of the traction rod. In fact, as presented in Fig. 1; when the displacement is small, the traction rod is softer. But when the traction rod is considered as a linear element, the related stiffness is constant and stiffer than the nonlinear traction rod.

Figures 9 and 10 present the PSD of bounce acceleration for the speed of $300 \mathrm{~km} / \mathrm{h}$ at positions $\mathrm{C}$ and $\mathrm{F}$, respectively. The peaks related to the nonlinear interaction appear in frequencies of $5.84 \mathrm{~Hz}$ and $19.19 \mathrm{~Hz}$. For the linear interaction case, the peaks appear in frequencies of $6.58 \mathrm{~Hz}$ and $20.27 \mathrm{~Hz}$. Another point that is clear from these results is the change in the bending modes' amplitudes and frequencies in bounce acceleration response of the carbody. As is clear from Fig. 9, the peak amplitude of the first bending mode in the PSD of bounce acceleration at position $\mathrm{C}$ is $0.19175\left(\mathrm{~m} / \mathrm{s}^{2}\right)^{2} / \mathrm{Hz}, 0.1049$ $\left(\mathrm{m} / \mathrm{s}^{2}\right)^{2} / \mathrm{Hz}$, and $0.145\left(\mathrm{~m} / \mathrm{s}^{2}\right)^{2} / \mathrm{Hz}$ for the cases without interaction, with linear interaction, and with nonlinear interaction, respectively. At the same time, the related frequencies are $9.84 \mathrm{~Hz}, 10.38 \mathrm{~Hz}$, and
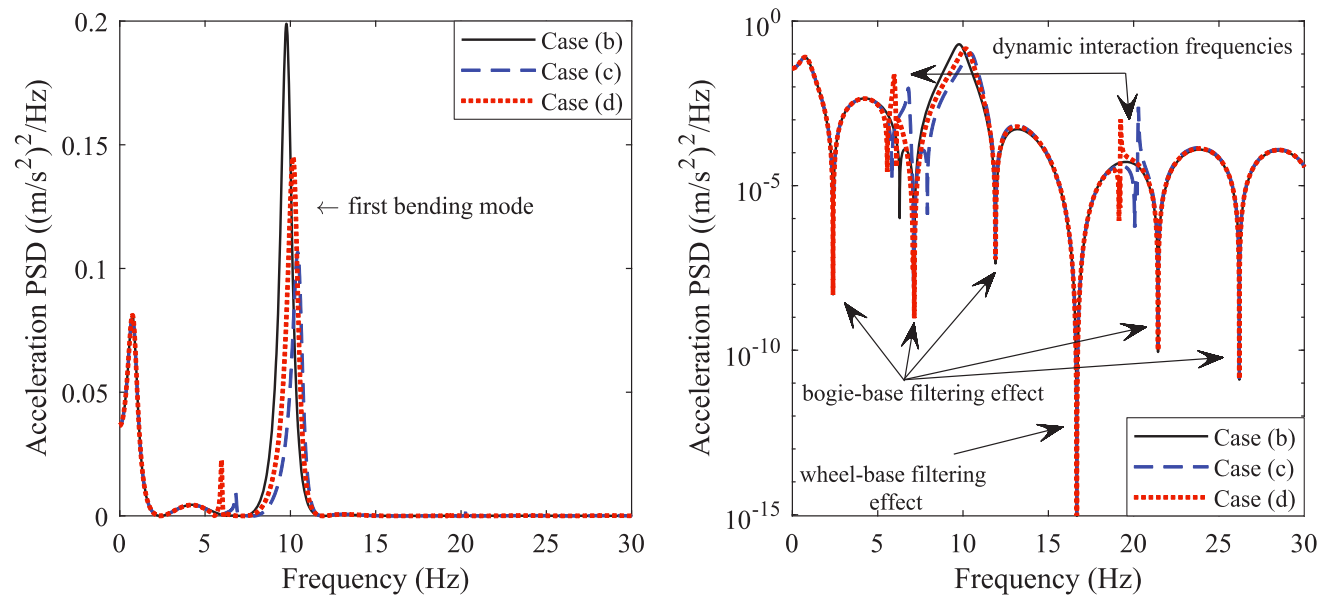

Fig. 9. PSD of bounce acceleration at position $\mathrm{C}$ with and without considering the dynamic interaction. Linear (left) and logarithmic (right) scale plots.
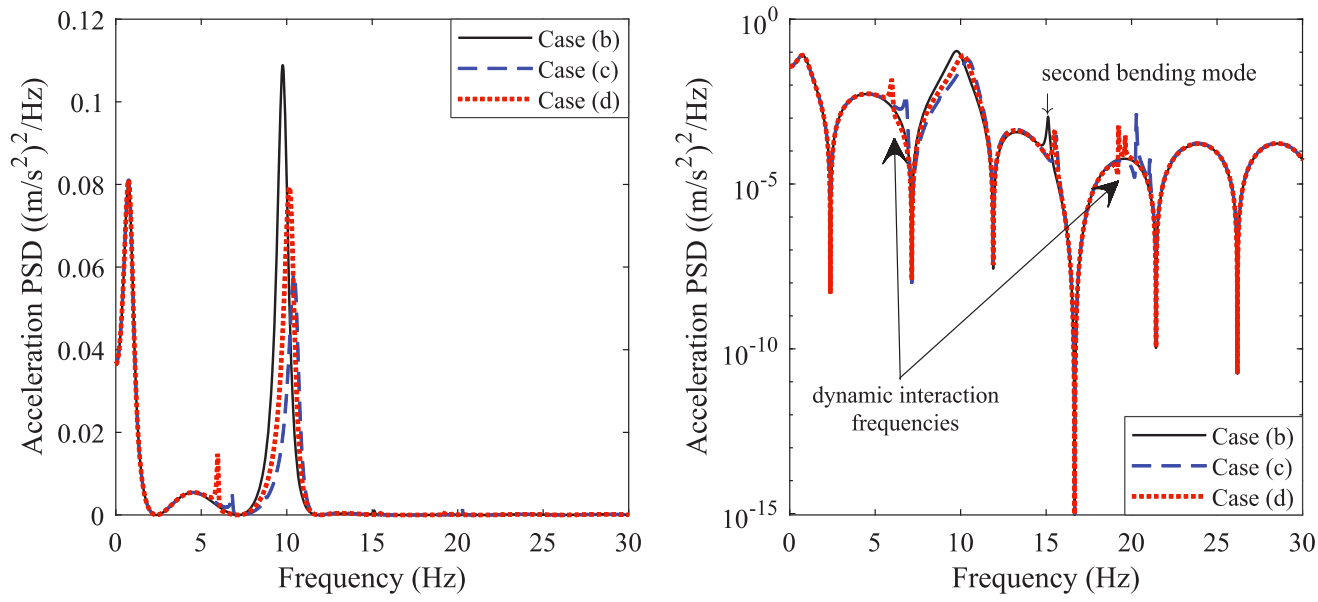

Fig. 10. PSD of bounce acceleration at position $\mathrm{F}$ with and without considering the dynamic interaction. Linear (left) and logarithmic (right) scale plots. 
$10.15 \mathrm{~Hz}$, respectively. Indeed, the anti-resonance, which appears immediately after the resonance of the dynamic interaction, cancels a part of the first bending mode peak; therefore, the peak frequency of this mode changed, and consequently, the amplitude reduced.

These changes on the frequency and amplitude in the peak of the first bending mode on the carbody's bounce acceleration affect the ride quality index. This is since the carbody's first bending mode influences the ride quality index significantly [3]. From Fig. 10, a similar scenario happens for the bounce acceleration at position $\mathrm{F}$. The resonance value of the first bending mode on the bounce acceleration is changed from $0.1089\left(\mathrm{~m} / \mathrm{s}^{2}\right)^{2} / \mathrm{Hz}$ for the case without interaction to $0.0792\left(\mathrm{~m} / \mathrm{s}^{2}\right)^{2} / \mathrm{Hz}$ and $0.0574\left(\mathrm{~m} / \mathrm{s}^{2}\right)^{2} / \mathrm{Hz}$ for cases with linear interaction and nonlinear interaction, respectively. At the same time, the peak value of the second bending mode on the bounce acceleration is decreased from $0.001096\left(\mathrm{~m} / \mathrm{s}^{2}\right)^{2} / \mathrm{Hz}$ for the case without interaction to $0.000395\left(\mathrm{~m} / \mathrm{s}^{2}\right)^{2} / \mathrm{Hz}$ and $0.000274\left(\mathrm{~m} / \mathrm{s}^{2}\right)^{2} / \mathrm{Hz}$ for cases with linear interaction and nonlinear interaction, respectively. The corresponding frequencies also changed; for the first bending modes, the peak frequency moved from $9.84 \mathrm{~Hz}$ to $10.38 \mathrm{~Hz}$ and $10.14 \mathrm{~Hz}$; and for the second bending mode, it moved from $15.12 \mathrm{~Hz}$ to $15.49 \mathrm{~Hz}$ and $15.6 \mathrm{~Hz}$ for the cases with linear interaction and nonlinear interaction, respectively. These changes on the amplitudes and frequencies of the peaks relevant to the first and second bending mode can affect the ride quality index. This issue is further examined in the next section of this article.

\subsection{Evaluation of the vertical ride quality}

In this section, the ride quality indexes due to the bounce carbody motions (vertical ride quality index from here on) for various vehicle velocities are assessed. The valuation is based on the EN 12299 standard. Figure 11 presents the vertical ride quality index for various velocities at positions $\mathrm{C}$ (center of the carbody floor) and $\mathrm{F}$ (above the front bogie of the carbody floor). The results are obtained for the following cases: rigid carbody, flexible carbody without interaction, flexible carbody with linear interaction, and flexible carbody with nonlinear interaction. As displayed, the vertical ride quality index at

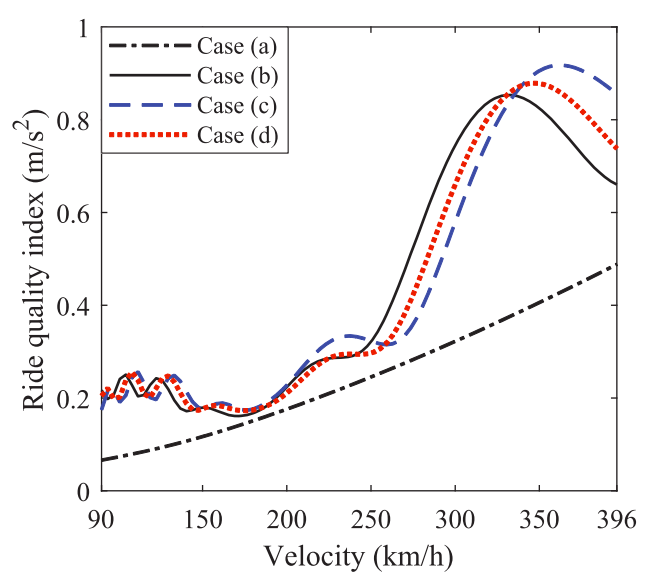

position $\mathrm{C}$ is larger than position $\mathrm{F}$; this is due to the influence of the first flexural bending mode, which significantly affects the ride quality. This mode is much more sensed at position $\mathrm{C}$ than position $\mathrm{F}$. Therefore, the corresponding ride quality at position $\mathrm{C}$ worsened. The ride quality index for the speed of $300 \mathrm{~km} / \mathrm{h}$ at position $\mathrm{C}$ is 0.745 $\mathrm{m} / \mathrm{s}^{2}, 0.58 \mathrm{~m} / \mathrm{s}^{2}$, and $0.66 \mathrm{~m} / \mathrm{s}^{2}$ for cases (b), (c), and (d), respectively. The immediate outcome is that the inclusion of the dynamic interaction in the model improves the ride quality index.

When the traction rod is considered linear, the ride quality index is reduced for 22.1 percent. In contrast, if the traction rod is assumed as a nonlinear element, the ride quality index reduces for 11.4 percent. This is due to the frequency where the dynamic interaction resonance occurs. When the traction rod modeled as a linear element, the peaks relevant to the dynamic interaction occur in higher frequencies compared with the case in which the traction rod is assumed as a nonlinear element. For the running speed of $300 \mathrm{~km} / \mathrm{h}$, the frequency of linear dynamic interaction is $6.58 \mathrm{~Hz}$, while for nonlinear dynamic interaction is $5.84 \mathrm{~Hz}$; consequently, a larger part of the peak associated with the first bending mode in bounce acceleration canceled by the linear dynamic interaction. Therefore, the ride quality index for the linear dynamic interaction is smaller than the nonlinear dynamic interaction. For the ride quality index at position $\mathrm{F}$, a similar scenario happens where the ride quality indexes are $0.6 \mathrm{~m} / \mathrm{s}^{2}, 0.494 \mathrm{~m} / \mathrm{s}^{2}$, and $0.546 \mathrm{~m} / \mathrm{s}^{2}$ for cases (b), (c), and (d), respectively. The ride quality index is decreased by 17.6 percent for the case (c) in comparison with case (b), while this reduction for case (d) rather than case (b) is 9 percent. Moreover, bogie-carbody dynamic interaction causes an increment in speed that exhibits the worst ride quality index.

Therefore, in the case where the dynamic interaction is not considered, the worst situation for the vertical ride quality happens at the speed of $333 \mathrm{~km} / \mathrm{h}$ and $337 \mathrm{~km} / \mathrm{h}$ for $\mathrm{C}$ and F positions, respectively. The related values of the ride quality indexes are $0.854 \mathrm{~m} / \mathrm{s}^{2}$ and $0.694 \mathrm{~m} / \mathrm{s}^{2}$, respectively. In contrast, when the linear dynamic interaction through the traction rod is considered, the most significant ride quality indexes are $0.918 \mathrm{~m} / \mathrm{s}^{2}$ and $0.758 \mathrm{~m} / \mathrm{s}^{2}$. They occur at the vehicle running speed of $364 \mathrm{~km} / \mathrm{h}$ and $369 \mathrm{~km} / \mathrm{h}$ for C and F positions, respectively. For the nonlinear dynamic interaction case, the critical situation for the ride quality index occurs at the running

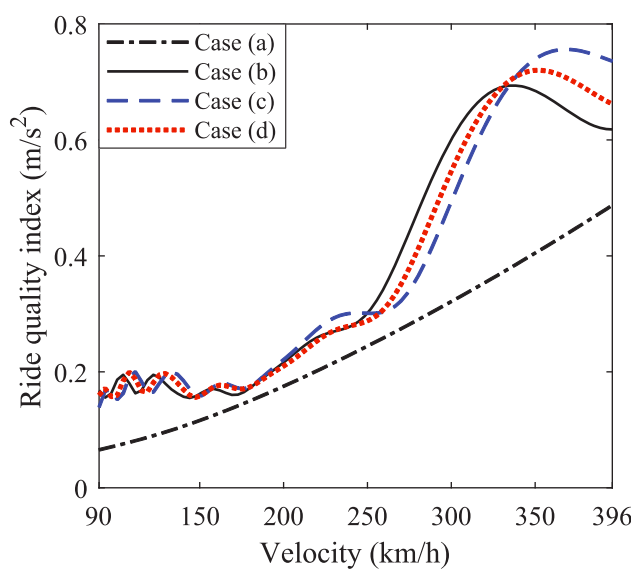

Fig. 11. Vertical ride quality index for various running speeds, at position $C$ (left) and at position $F$ (right). 
speeds of $348 \mathrm{~km} / \mathrm{h}$ and $352 \mathrm{~km} / \mathrm{h}$, whereas corresponding values for the positions $C$ and $F$ are $0.879 \mathrm{~m} / \mathrm{s}^{2}$ and $0.72 \mathrm{~m} / \mathrm{s}^{2}$, respectively. The increase of vertical ride quality index when bogie-carbody dynamic interaction is considered relates to the resonances associated with the bogie-carbody dynamic interaction, which appears in the spectrum of the carbody's bounce acceleration, as presented in Figs. 9 and 10. In these figures, some resonances appear in the frequencies from $4 \mathrm{~Hz}$ to $20 \mathrm{~Hz}$, which are the significant frequency range regarding the vertical ride quality index according to the EN12299 standard [27].

From Fig. 9, the peak amplitude of the first bending mode in the PSD of bounce acceleration at position $\mathrm{C}$ is $0.19175\left(\mathrm{~m} / \mathrm{s}^{2}\right)^{2} / \mathrm{Hz}$, $0.1049\left(\mathrm{~m} / \mathrm{s}^{2}\right)^{2} / \mathrm{Hz}$, and $0.145\left(\mathrm{~m} / \mathrm{s}^{2}\right)^{2} / \mathrm{Hz}$ for the cases without interaction, with linear interaction, and with nonlinear interaction, respectively. At the same time, the related frequencies are $9.84 \mathrm{~Hz}, 10.38$ $\mathrm{Hz}$, and $10.15 \mathrm{~Hz}$, respectively. Indeed, the anti-resonance, which appears immediately after the resonance of the dynamic interaction, cancels a part of the first bending mode peak; therefore, the peak frequency of this mode is changed, and consequently, the amplitude reduced.

Figure 12 illustrates the effect of changing the first bending mode frequency on the vertical ride quality index at position $\mathrm{C}$ for the speed of $300 \mathrm{~km} / \mathrm{h}$. In this figure, it assumed that the carbody mass is constant. When the dynamic interaction is not considered, the worst situations for the vertical ride quality index occur at frequencies of about $5 \mathrm{~Hz}$ and $10 \mathrm{~Hz}$. Indeed, near these frequencies, the first flexural bending mode is not impressed by the bogie-base or the wheel-base filtering effect. Therefore, the most significant value for the vertical ride quality index occurs at these frequencies. When dynamic interaction is considered, the results demonstrate 9.1 percent and 21.4 percent enhancements on the ride quality index at a frequency of $5 \mathrm{~Hz}$ for the linear and nonlinear interaction cases, respectively. At the frequency of $9.5 \mathrm{~Hz}$, the ride quality index is improved 17.7 percent and 5.7 percent by the linear and nonlinear dynamic interaction, respecti vely. While at the frequencies between $5 \mathrm{~Hz}$ to $10 \mathrm{~Hz}$, when the dynamic interaction is not considered, the vertical ride quality index is improved; particularly at the frequency of $7.5 \mathrm{~Hz}$, an im-

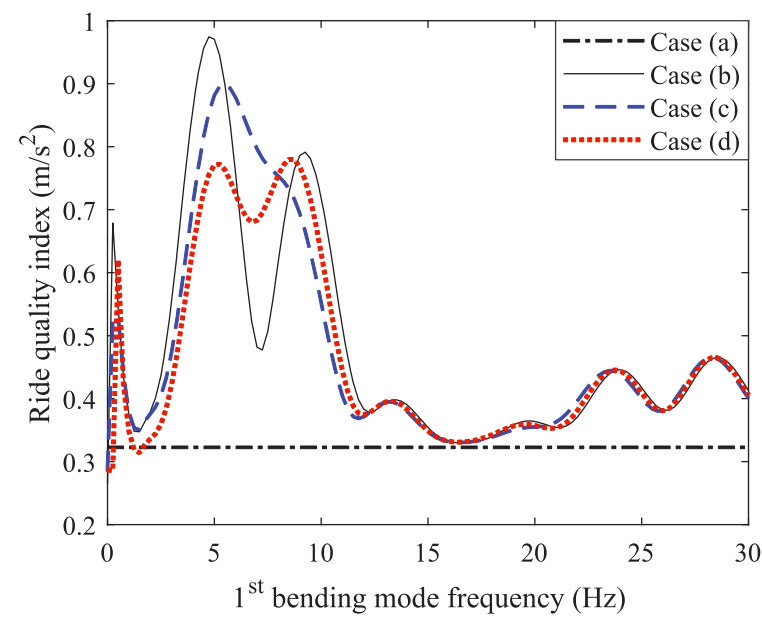

Fig. 12. The effect of the first flexural bending mode frequency on the vertical ride quality index at position $\mathrm{C}$. provement of 51 percent is evident in the ride quality index. However, when the dynamic interaction investigated in the modeling, the ride quality index at this frequency worsens, where the vertical ride quality index increased from $0.48 \mathrm{~m} / \mathrm{s}^{2}$ for the case without interaction to $0.0 .795 \mathrm{~m} / \mathrm{s}^{2}$ and $0.68 \mathrm{~m} / \mathrm{s}^{2}$ for linear and nonlinear interaction cases, respectively. These negative changes in ride quality index at the frequency of $7.5 \mathrm{~Hz}$ is due to the dynamic interaction since the first bending mode is approximately canceled at this frequency. Also, at frequencies higher than $13 \mathrm{~Hz}$, the influence of the carbody's flexural bending motion is drastically reduced; therefore, at these frequencies (larger than $13 \mathrm{~Hz}$ ), the vertical ride quality index is not considerably influenced via the bogie-carbody dynamic interaction.

\subsection{The effect of bogie-base distance on the bounce vibration of the carbody}

Figure 13 demonstrates the PSD of bounce acceleration at position $\mathrm{C}$ while the longitudinal distance between two bogies is changed. These results are for the speed of $300 \mathrm{~km} / \mathrm{h}$ by considering the linear and nonlinear dynamic interaction. The first point that is observable from the figure is that the frequencies associated with the filtering effect of bogie-base are changed. This is because these frequencies are a function of the longitudinal distance between bogie centers.

From Fig. 13 (a), (b), and (c), it inferred that the most significant bounce acceleration for the speed of $300 \mathrm{~km} / \mathrm{h}$ occurs for the case where the bogies distance is $8.25 \mathrm{~m}$. Indeed, in this case, the first
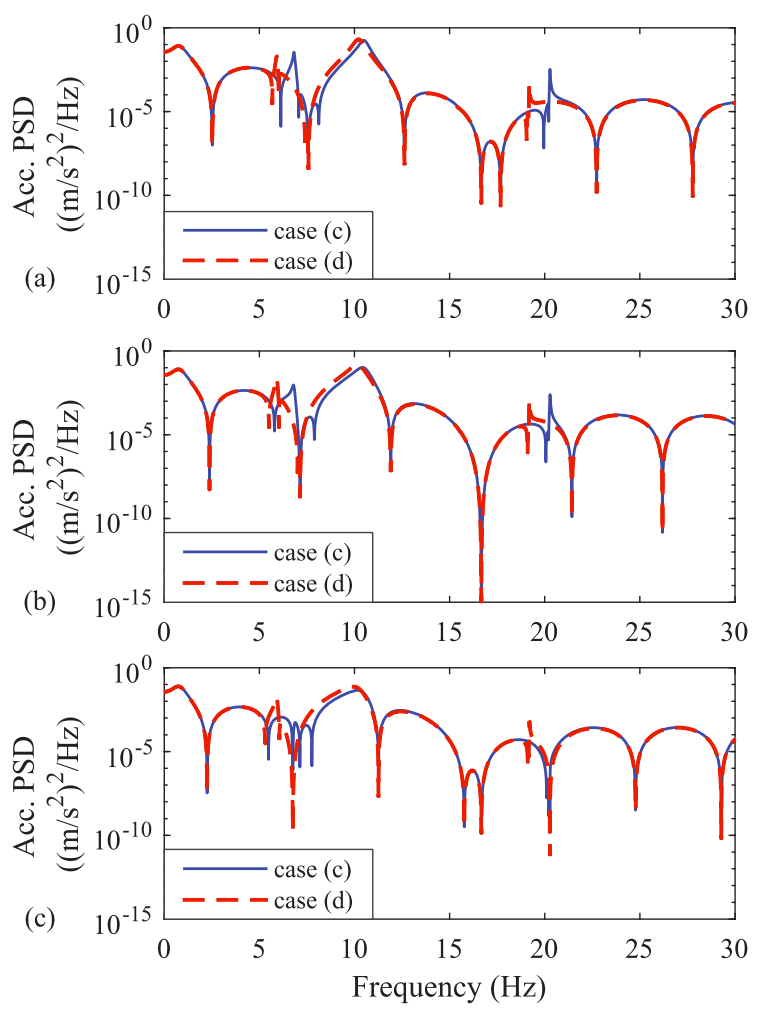

Fig. 13. The effect of bogie-base distance on the bounce acceleration at position C; a) $l_{b}=8.25 \mathrm{~m}$, b) $l_{b}=8.75 \mathrm{~m}$, and c) $l_{b}=9.25 \mathrm{~m}$. 
bending mode is not affected by the filtering effect, and the linear dynamic interaction cancels only a small part of the first bending mode. While for the other two cases in addition to the linear interaction, the filtering effect also affects the first bending mode. Therefore, for these cases, and particularly in the third case, the first bending mode canceled more than the first case. Hence, it can be predicted that the vertical ride quality index is better for case three $\left(l_{b}=9.25 \mathrm{~m}\right)$ than the two first cases.

Figure 14 presents the vertical ride quality index at position $\mathrm{C}$ when the bogies' longitudinal distance is changed. At some speeds, for example, between the running speeds of $280 \mathrm{~km} / \mathrm{h}$ to $350 \mathrm{~km} / \mathrm{h}$, the vertical ride quality index worsens when the interaction is considered nonlinear instead of linear. At the running speed of $300 \mathrm{~km} / \mathrm{h}$, when the linear interaction investigated, the ride quality index enhanced by 14 percent by increasing the bogies distance from $8.75 \mathrm{~m}$ to $9.25 \mathrm{~m}$, where the relevant ride quality indexes are $0.569 \mathrm{~m} / \mathrm{s}^{2}$ and $0.489 \mathrm{~m} / \mathrm{s}^{2}$ for the bogies distance of $8.75 \mathrm{~m}$ and $9.25 \mathrm{~m}$, respectively. For the nonlinear interaction case also, the ride quality indexes are $0.652 \mathrm{~m} / \mathrm{s}^{2}$ and $0.582 \mathrm{~m} / \mathrm{s}^{2}$ for the bogies distance of $8.75 \mathrm{~m}$ and 9.25 $\mathrm{m}$, respectively, which presents a 10.7 percent improvement in the ride quality index. However, increasing the bogies distance improved the carbody's vertical ride quality index at a running speed of 300 $\mathrm{km} / \mathrm{h}$ for both linear and nonlinear interaction. Meanwhile, this can negatively affect the vehicle's dynamic behavior, such as hunting stability, curving performance, etc.

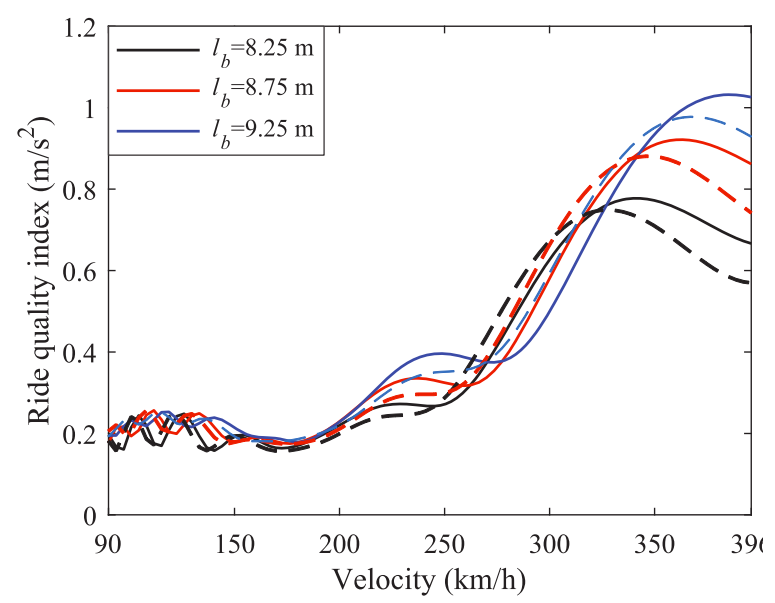

Fig. 14. The effect of bogie-base distance on the vertical ride quality index at position $\mathrm{C}$, with linear interaction (unbroken line) and nonlinear interaction (dashed line).

\section{Conclusions}

The existence of dynamic interaction between carbody flexural bending motion and bogie frames longitudinal motion is reported in the relevant literature. This dynamic interaction comes from use of traction rod element that was considered as a linear element in the prior studies. In the present work, the traction rod is considered as a nonlinear element to facilitate a more precise study into dynamic behavior of rail vehicle carboy bounce vibrations. The equivalent linearization method is used for the nonlinear analysis of the dynamic of a high-speed railway vehicle in the frequency domain. The vehicle model included fifteen degrees of freedom and represented a
Shinkansen high-speed railway vehicle (series 100) with an aluminum alloy carbody. The model included the first and the second flexural bending modes of the carbody. Excitation on the vehicle comes from a track irregularity corresponding to the track class 6 from the FRA regulations. The simulation results are compared with the results of running tests and the time-domain solution of the nonlinear model The results from the equivalent linearization method demonstrate satisfactory levels of accuracy. The outcome of dynamic interaction between carbody and bogie frames on bounce vibrations of carbody examined based on such an innovative model. The following results attained:

1. The bounce acceleration of carbody floor reveals that carbody almost behaves like a rigid body under the train speed of $200 \mathrm{~km} / \mathrm{h}$. It is verified that this is due to the bogie-base and wheel-base filtering effects.

2. The maximum bounce acceleration relevant to the first bending mode at the center of the carbody is increased by 38.2 percent for the speed of $300 \mathrm{~km} / \mathrm{h}$ when the dynamic interaction is considered as nonlinear instead of linear. Therefore, considering the nonlinearity of the traction rod improves the accuracy of results.

3. When dynamic interaction is considered, some resonances appear in the spectrum content of bounce acceleration of carbody floor. These resonances are related to dynamic interaction between carbody and bogie frames. Since these peaks appear in the frequency range of $4 \mathrm{~Hz}$ to $20 \mathrm{~Hz}$; therefore, the vertical ride quality index is affected negatively.

4. The inclusion of nonlinear interaction causes a reduction of the frequency of the peak relevant to dynamic interaction. However, peak attenuation associated with the first bending mode on the bounce acceleration response is higher with the inclusion of a linear interaction. As a result, the ride quality index with the nonlinear interaction increased for 13.7 percent when the train traveled at the speed of $300 \mathrm{~km} / \mathrm{h}$ in comparison with the linear case.

5. The effect of changing bogies longitudinal distance on ride quality index examined. The ride quality index improved for 10.7 percent at the running speed of $300 \mathrm{~km} / \mathrm{h}$ when the bogie base increased from $8.75 \mathrm{~m}$ to $9.25 \mathrm{~m}$.

\section{Acknowledgment}

The authors gratefully acknowledge precious remarks and valuable propositions from Professor Takahiro Tomioka during this research. The third author would also like to acknowledge the funds provided by the NVTRail project (Noise and Vibrations induced by railway traffic in tunnels: an integrated approach), funded by FEDER funds through COMPETE2020 and by national funds (PIDDAC) through FCT/MCTES, with grant reference POCI-01-0145-FEDER-029577; and by the VIBWAY project (Fast computational tool for railwayinduced vibrations and re-radiated noise assessment), with reference RTI2018-096819-B-I00, supported by the Ministerio de Ciencia e Innovación, Retos de Investigación 2018.

\section{Nomenclature}

E Young's modulus of the carbody's material 
I the second moment of the cross-sectional area of the carbody with respect to its neutral axis

$c_{y} \quad$ yaw damping coefficient per bogie

$c_{z p} \quad$ vertical damping of the primary suspension

$c_{z s} \quad$ vertical damping of the secondary suspension at each side of the bogie

$h_{b} \quad$ the vertical distance from the center of gravity (COG) of the wheelset to COG of the bogie

$h_{c}$ the vertical distance from the traction rod to COG of the carbody

$h_{y}$ the vertical distance from the yaw damper to COG of the carbody

$J_{b} \quad$ pitch moment of inertia of the bogie frame

$J_{c} \quad$ pitch moment of inertia of the carbody

$k_{h z}$ equivalent linear spring stiffness of the Hertzian contact

$k_{t L} \quad$ stiffness of the linear traction rod

$k_{x p} \quad$ longitudinal stiffness of the primary suspension

$k_{y} \quad$ stiffness of the yaw damper

$k_{z p} \quad$ vertical stiffness of the primary suspension

$k_{z s} \quad$ vertical stiffness of the secondary suspension at each side of the bogie

$l \quad$ carbody length

$l_{b} \quad$ half distance between the two bogie centers

$l_{c}$ the longitudinal position of the center of the carbody measured from its rear end

$l_{f} \quad$ the longitudinal position of the front secondary suspension on the carbody from its rear end

$l_{r} \quad$ the longitudinal position of the rear secondary suspension on the carbody from its rear end

$l_{t f} \quad$ the longitudinal position of the front bogie traction rod connection point with the carbody to the carbody rear end

$l_{t r} \quad$ the longitudinal position of the rear bogie traction rod connection point with the carbody to the carbody rear end

$l_{y f}$ the longitudinal position of the front bogie yaw damper connection point with the carbody to the carbody rear end

$l_{y r} \quad$ the longitudinal position of the rear bogie yaw damper connection point with the carbody to the carbody rear end

$l_{w} \quad$ half distance between the two wheelsets of the bogie

$m_{b} \quad$ bogie frame mass

$m_{c} \quad$ carbody mass

$m_{w} \quad$ wheelset mass

$r_{w} \quad$ wheel radius

$\omega_{1}$ frequency of the carbody first bending mode $\omega_{2}$ frequency of the carbody second bending mode

$\xi_{1} \quad$ structural damping coefficient of the first bending mode

$\xi_{2} \quad$ structural damping coefficient of the second bending mode

\section{References}

[1] T. Tomioka and T. Takigami. Reduction of bending vibration in railway vehicle carbodies using carbodybogie dynamic interaction. Vehicle System Dynamics, 2010, 48(sup 1):467-486.

[2] F. Ripamonti and A. Chiarabaglio. A smart solution for improving ride comfort in high-speed railway vehicles. Journal of Vibration and Control, 2019, 25(13):19581973.

[3] V. Bokaeian, M. A. Rezvani, and R. Arcos. The coupled effects of bending and torsional flexural modes of a high-speed train car body on its vertical ride quality. Proceedings of the Institution of Mechanical Engineers, Part K: Journal of Multi-body Dynamics, 2019, 233(4):979-993.

[4] Y. Akiyama, T. Tomioka, T. Takigami, K.-I. Aida, and T. Kamada. A three-dimensional analytical model and parameter determination method of the elastic vibration of a railway vehicle carbody. Vehicle System Dynamics, 2019, 55(4):545-568.

[5] C. Huang, J. Zeng, G. Luo, and H. Shi. Numerical and experimental studies on the car body flexible vibration reduction due to the effect of car body-mounted equipment. Proceedings of the Institution of Mechanical Engineers, Part F: Journal of Rail and Rapid Transit, 2018, 232(1):103-120.

[6] D. Gong, J. S. Zhou, and W. J. Sun. On the resonant vibration of a flexible railway car body and its suppression with a dynamic vibration absorber. Journal of Vibration and Control, 2012, 19(5):649-657.

[7] J. Zhou, R. Goodall, L. Ren, and H. Zhang. Influences of car body vertical flexibility on ride quality of passenger railway vehicles. Proceedings of the Institution of Mechanical Engineers, Part F: Journal of Rail and Rapid Transit, 2009, 223(5):461-471.

[8] M. Graa, M. Nejlaoui, A. Houidi, Z. Affi, and L. Romdhane. Development of a reduced dynamic model for comfort evaluation of rail vehicle systems. Proceedings of the Institution of Mechanical Engineers, Part K: Journal of Multi-body Dynamics, 2016, 230(4):489-504.

[9] C. Mizrak and İ. Esen. The optimisation of rail vehicle bogie parameters with the fuzzy logic method in order to improve passenger comfort during passage over bridges. International Journal of Heavy Vehicle Systems, 2017, 24(2):113-139.

[10] P. Antunes, H. Magalhães, J. Ambrósio, J. Pombo, and J. Costa. A co-simulation approach to the wheel-rail contact with flexible railway track. Multibody System Dynamics, 2019, 45(2):245-272.

[11] S. Pradhan and A. K. Samantaray. Integrated modeling and simulation of vehicle and human multi-body dynamics for comfort assessment in railway vehicles. Journal of Mechanical Science and Technology, 2018, 32(1):109-119.

[12] S. K. Sharma and A. Kumar. Ride comfort of a higher speed rail vehicle using a magnetorheological suspension system. Proceedings of the Institution of 
Mechanical Engineers, Part K: Journal of Multi-body Dynamics, 2018, 232(1):32-48.

[13] L. Ling, Q. Zhang, X. Xiao, Z. Wen, and X. Jin. Integration of car-body flexibility into train-track coupling system dynamics analysis. Vehicle System Dynamics, 2018, 56(4):485-505.

[14] M. Dumitriu and D. Stănică. Vertical bending vibration analysis of the car body of railway vehicle. In: IOP Conference Series: Materials Science and Engineering. Romania: IOP Publishing: 2019, 1-6.

[15] K. Xu, Z. Feng, H. Wu, F. Li, and C. Shao. Investigating the influence of rail grinding on stability, vibration, and ride comfort of high-speed EMUs using multi-body dynamics modelling. Vehicle System Dynamics, 2019, 57(11):1621-1642.

[16] J. Guo, H. Shi, R. Luo, and P. Wu. Parametric Analysis of the Car Body Suspended Equipment for Railway Vehicles Vibration Reduction. IEEE Access, 2019, 7:88116-88125.

[17] X. Zheng, A. Zolotas, and R. Goodall. Combined active suspension and structural damping control for suppression of flexible bodied railway vehicle vibration. Vehicle System Dynamics, 2019, 58(2):198-228.

[18] Y. Sun, J. Zhou, D. Gong, W. Sun, and Z. Xia. Vibration control of high-speed trains self-excitation under-chassis equipment by HSLDS vibration isolators. Journal of Mechanical Science and Technology, 2019, 33(1):65-76.

[19] S. Bruni, J. P. Meijaard, G. Rill, and A. L. Schwab. State-of-the-art and challenges of railway and road vehicle dynamics with multibody dynamics approaches. Multibody System Dynamics, 2020, 49(1):1-32.

[20] H. Magalhães, F. Marques, B. Liu, P. Antunes, J. Pombo, P. Flores, J. Ambrósio, J. Piotrowski, and S. Bruni. Implementation of a non-Hertzian contact model for railway dynamic application. Multibody System Dynamics, 2020, 48(1):41-78.

[21] L. Xiao, M. Wang, B. Zhang, and Z. Zhong. Vehicle roll stability control with active roll-resistant electrohydraulic suspension. Frontiers of Mechanical Engineering, 2020, 15(1):43-54.

[22] A. W. Leissa and M. S. Qatu. Vibrations of Continuous Systems. 1st ed. New York: McGraw-Hill Companies, 2011, 103-114.

[23] T. Takigami and T. Tomioka. Modal vibration analysis of recent railway vehicles. In: Proceedings of the 12th Asia Pacific Vibration Conference (APVC2007). Sapporo, Japan: 2007, 1-8.

[24] J. B. Roberts and P. D. Spanos. Random vibration and statistical linearization. New York: Courier Corporation, 2003, 177-202.

[25] L. Fryba. Dynamics of Railway Bridges. 2nd ed. London: Thomas Telford Publishing, 1996, 120-129.

[26] V. K. Garg and R. V. Dukkipati. Dynamics of Railway Vehicle Systems. 1st ed. NEw York: Academic Press, 1984, 80-91.

[27] BS EN 12299. Railway Applications. Ride Comfort for Passengers. Measurement and Evaluation. 2009.

\section{Author information}

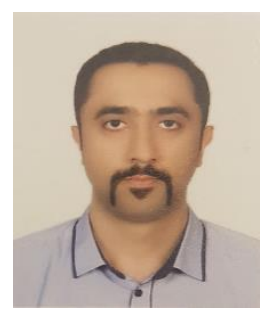

Vahid Bokaeian received his MSc in Railway Engineering (Rolling Stocks) from Iran University of Science and Technology in 2013. He is currently a Ph.D. candidate at the same university. His research interests include railway vehicle dynamics, flexible vibration of carbody, random vibration, and vehicle ride comfort. He was an academic visitor in the Acoustical and Mechanical Engineering Laboratory of Universitat Politècnica de Catalunya for nine months in 2018.

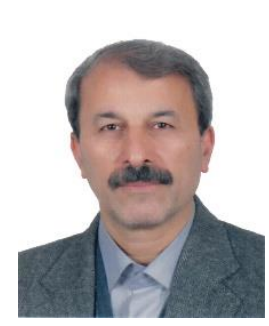

Mohammad Ali Rezvani holds a Ph.D. in mechanical engineering from the University of New South Wales in Sydney, Australia, since 1995 . He is an associate professor at the School of Railway Engineering at Iran University of Science and Technology. His areas of expertise include rotor dynamics, modal analysis, control of vibrations, and vehicle dynamics. He is a member of the national committee for the condition monitoring and fault diagnosis of machinery in Iran.

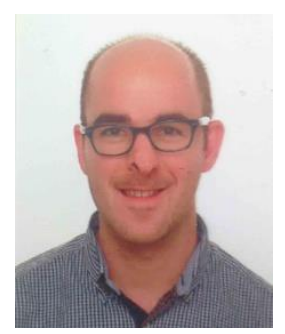

Robert Arcos Villamarin graduated as an industrial engineer from the Universitat Politècnica de Catalunya (UPC) in 2008, and he gets his $\mathrm{Ph} . \mathrm{D}$. degree in Mechanical Engineering, from the same university, in 2011. He was an academic visitor in the Institute of Sound and Vibration Research (ISVR) of the University of Southampton, and post-doctoral researcher of the Faculdade de Engenharia da Universidade do Porto for periods of 12 and 15 months, respectively. He is currently an associate professor of the Mechanical Engineering Department of the UPC, working in the research group Acoustical and Mechanical Engineering Laboratory (LEAM). His research interests include railway-induced noise and vibration, mechanical characterization of railway track components, construction-induced noise and vibration, building dynamics, railway vehicle dynamics, vibration energy harvesting, and pantograph/catenary interaction. 